\title{
AC 2012-3320: A SIMPLE GRAPHICAL METHOD TO ASSESS INDUC- TION MACHINE PERFORMANCE USING PER PHASE CURRENT AS THE CONTROLLING VARIABLE IN LIEU OF PERUNIT SLIP
}

\section{Prof. Donald L. Skaar, San Diego State University}

Donald L. Skaar received the five-year bachelor's of electrical engineering degree from the University of Minnesota in 1949 and the master's of science degree with a major in electrical engineering from Oregon State University in 1966. He worked in the aerospace industry for a number of years for Honeywell, Convair Astronautics, and Kinetics Teledyne. He was a faculty member in the Department of Electrical and Computer Engineering at San Diego State University for more than 40 years and is a Professor Emeritus of that institution. His email address is dskaar@mail.sdsu.edu. 


\title{
A Simple Graphical Method To Assess Induction Machine Performance Using Current As The Controlling Variable In Lieu Of Per Unit Slip
}

\begin{abstract}
Fixed-frequency induction machines remain the most widely-used electromechanical energy conversion devices encountered in engineering practice; therefore a very simple and insightful assessment of machine performance should be of interest to faculty members and students across the engineering spectrum. The per-phase electrical model illustrated in IEEE Standard 112 has been used by most authors of engineering textbooks in a traditional analysis of induction machines - almost exclusively motors - using 'per unit slip' as the controlling variable. The concept of per unit slip is admittedly brilliant; however, the traditional method of analysis based upon that term is tedious, requires a repetition of the most cumbersome steps for each specific machine speed of interest, and lacks insight. In contrast the proposed analysis offers a graphical assessment of the same model using the magnitude of the current as the controlling variable. Analysts need only draw an Impedance Line and Resistance Line for a specific current magnitude upon a circular plot designated as the Lumped Loss Normalized Impedance Locus before completing an assessment of a machine. While valuable to electrical engineering power majors because of its simplicity and insightful approach, it is particularly-suited for engineers/students outside that specialty who wish to assess induction machine performance without having to deal with per unit slip, synchronous speed, and the manipulation of complex numbers associated with traditional analysis. With the widespread contemporary interest in "green" energy generation, an assessment of induction generators is increasingly important. Such an assessment is easily amenable to the method. It is important to note that for either motor or generator operation, there is one very definitive operating point on the periphery of the circular Locus for each specific value of current; one may easily visualize how that operating point moves around the periphery of the circle as the current varies.
\end{abstract}

Key Words: Single phase and polyphase induction machines; circle diagrams

\subsection{Introduction}

'Circle Diagrams' were in use over a century ago to aid in the qualitative assessment of induction machine performance under varying load conditions; they are now rarely seen unless computergenerated by one of the many programs now available for a detailed machine analysis. $\mathrm{H}$. $\mathrm{H}$. Skilling, the preeminent Stanford University engineer-educator, writing in his classic and widelyadopted network text ${ }^{1}$ of some five decades ago, stated, "The familiar Chinese Proverb valuing one picture above ten thousand words applies emphatically to circuit theory". He went on to describe the admittance circle diagram for a simplified electrical model of an induction motor, and also showed how an admittance circle could be transformed into an impedance circle. Traditionally, induction motor circle diagrams have been plots of admittance, were often tedious to construct, and the accuracy of the numerical results was questionable at best. In contrast, the circle diagram proposed here, dubbed the Lumped Loss Normalized Impedance Locus - or more simply the Locus - can be developed easily from a Unit Circle that is derived from the Two Element Model of a machine. The proposed method, while obviously lacking the accuracy of a computer analysis, yields measured results that are accurate to within a few percent so long as the Unit Circle has a diameter of at least 20 centimeters. 
The 'most complete' electrical models of three phase induction machines predominantly used by authors of engineering texts are duplicates of those illustrated in IEEE Standard $112^{2}$, the IEEE Standard Test Procedure for Polphase Induction Motors and Generators. The six-element-perphase electrical model shown in Figure 1 is duplicated from the 1996 version of that Standard; later versions use an equivalent seven-element-per phase model. Irrespective of the model used, former and present-day authors of engineering texts provide an analysis of induction machines (almost exclusively motors) using 'per unit slip' as the controlling variable. The concept of per unit slip is admittedly brilliant; however, the traditional method of analysis based upon that term is tedious, requires a repetition of the most cumbersome steps for each specific machine speed of interest, and does not provide insight into the inherently circular nature of the current-voltage relationship of an induction machine.

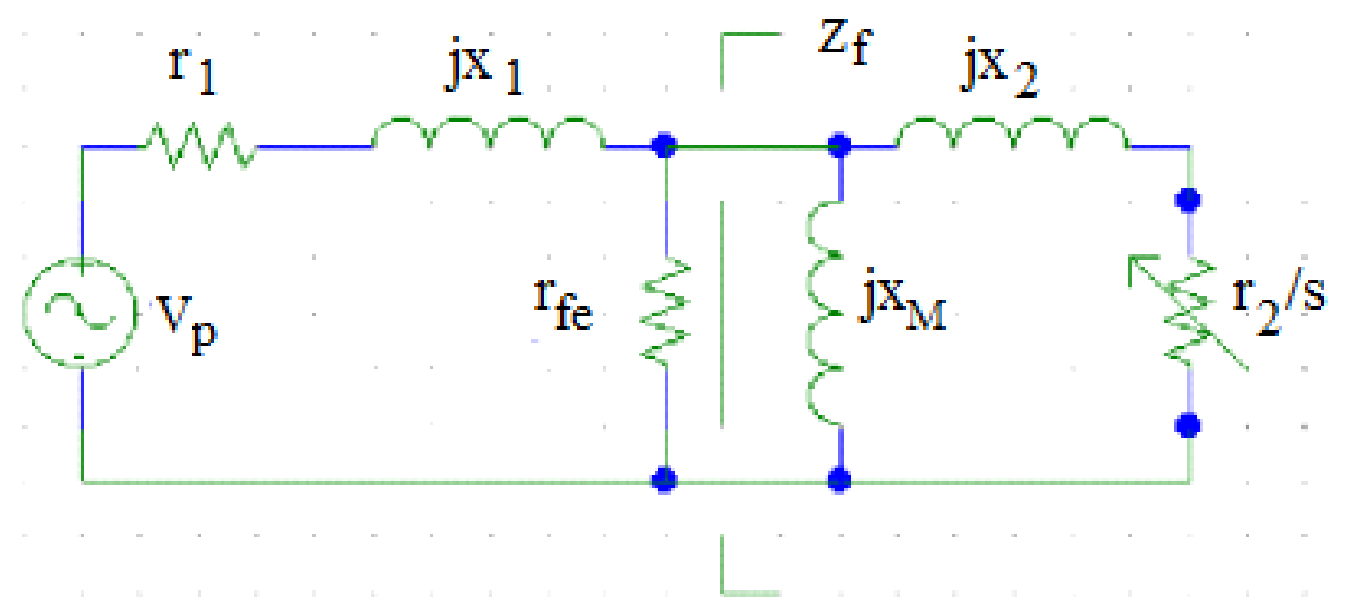

Figure 1. The IEEE Standard 112 Per-Phase Model of an Induction Machine (1996)

The elements of Figure 1 are described as follows:

$\mathrm{r}_{1}-$ the stator winding resistance;

$\mathrm{jx}_{1}-$ the impedance representing the stator leakage flux;

$\mathrm{jx}_{2}$ - the impedance, reflected to the stator, representing the rotor leakage flux;

$\mathrm{r}_{\mathrm{fe}}-$ the resistance representing the stator core loss;

$\mathrm{jx}_{\mathrm{M}}$ - the impedance representing the mutual flux shared by the stator and rotor windings; and

$\mathrm{r}_{2} / \mathrm{s}$ - the resistance representing the rotor resistance and shaft load - both reflected to the stator.

The relative magnitudes are as follows: $\mathrm{r}_{1}, \mathrm{r}_{2}, \mathrm{j} \mathrm{x}_{1}$, and $\mathrm{j} \mathrm{x}_{2}$ are of the same order of magnitude and usually much less than unity (the larger the machine, the smaller the values); $j \mathrm{x}_{\mathrm{M}}$ is almost two orders of magnitude larger than the $\mathrm{jx}_{2}$; and $\mathrm{r}_{\mathrm{fe}}$ is usually several times larger than $\mathrm{jx}_{\mathrm{M}}$. The element $r_{f e}$ is disregarded more often than not by authors when numerical examples are considered; with $\mathrm{r}_{\mathrm{fe}}$ removed, the resulting model has been referred to in the literature as the Steinmetz Model. As will be developed, the two most important model elements are $\mathrm{r}_{2} / \mathrm{s}$ and $\mathrm{j} \mathrm{x}_{\mathrm{M}}$; they largely determine the electrical characteristics of the machine under running conditions. By convention, it has been assumed that the only model element that may vary under normal machine operation is $r_{2} / s$, and the material proposed here relies upon that same assumption. 
To initiate the traditional analysis, one has to solve for the magnitude and phase of the input impedance of Figure 1 using the per unit slip 's' as the controlling variable. Writing the equation for that impedance in symbol form is straight-forward and may be written by inspection:

$$
\mathrm{Z}_{\mathrm{p}}=\mathrm{r}_{1}+\mathrm{j} \mathrm{x}_{1}+1 /\left[\left(1 / \mathrm{r}_{\mathrm{fe}}\right)+\left(1 / \mathrm{j} \mathrm{x}_{\mathrm{M}}\right)+1 /\left(\mathrm{j} \mathrm{x}_{2}+\mathrm{r}_{2} / \mathrm{s}\right)\right]
$$

However, when numerical model element values are inserted into Equation (1), a computer or a scientific calculator is needed to solve for that impedance. In contrast, the proposed analysis offers a simple graphical assessment using the magnitude of the current as the controlling variable. Analysts need only draw an Impedance Line and Resistance Line for a specific current magnitude upon a circular plot designated as the Lumped Loss Normalized Impedance Locus before initiating a reasonably-complete machine assessment using the simplest of calculators. In the material that follows, more-obvious equations are not numbered.

\subsection{Discussion}

A basic sense of the Locus may be gained by an examining the input impedance of Figure 1 with $r_{f e}$ neglected since it does not appreciably affect the diameter nor location of the circular portion of the impedance plot; the effect of $\mathrm{r}_{\mathrm{fe}}$ on the peripheral slip calibration is discussed in a 1998 IEEE paper ${ }^{3}$. While the magnitude of the per unit slip is in fact very much smaller than 1.0 under running conditions, herein it will be treated simply as a mathematical variable that can take on any negative or positive value from zero to infinity; an infinite slip is nonsensical in the real world but mathematically convenient. Figure 2 below is the exact geometric equivalent of the Steinmetz Model of a machine - Figure 1 with $\mathrm{r}_{\mathrm{fe}}$ removed. The input impedance of that Steinmetz Model may be expressed in equation form as:

$$
\mathrm{Z}=\mathrm{r}_{1}+\mathrm{j} \mathrm{x}_{1}+\mathrm{Z}_{\mathrm{f}}
$$

The term $Z_{\mathrm{f}}$ in Figure 1 has been defined in the technical literature as the Forward Impedance and that same nomenclature is used here; the fact that $Z_{\mathrm{f}}$ is circular (see the Appendix) eases the development of Figure 2. Observe $Z_{\mathrm{f}}$ in Figure 1 as the term 's' varies:

When $\mathrm{s}=0, \mathrm{r}_{2} / \mathrm{s}$ is an open circuit and $\mathrm{Z}_{\mathrm{f}}=\mathrm{j} \mathrm{x}_{\mathrm{M}}=\mathrm{Z}_{\mathrm{fmax}}$, its maximum value.

When $\mathrm{s}$ is infinite, $\mathrm{r}_{2} / \mathrm{s}$ is a short circuit so $\mathrm{Z}_{\mathrm{f}}=\mathrm{j}\left[\mathrm{x}_{\mathrm{M}} \| \mathrm{x}_{2}\right]=\mathrm{Z}_{\text {fminin }}$, its mimimum value.

Since the Forward Impedance locus is circular, the diameter may be defined as D, a very important machine constant that allows students to transform an actual impedance into a normalized impedance for use with a Locus - or visa versa; that constant is defined as:

$$
\mathrm{D}=\left|\left[\mathrm{Z}_{\mathrm{fmax}}-\mathrm{Z}_{\mathrm{fmin}}\right]\right|=\left[\mathrm{x}_{\mathrm{M}}-\left(\mathrm{x}_{\mathrm{M}} \| \mathrm{x}_{2}\right)\right]=\left[\mathrm{x}_{\mathrm{M}}-1 /\left(1 / \mathrm{x}_{\mathrm{M}}+1 / \mathrm{x}_{2}\right)\right]
$$




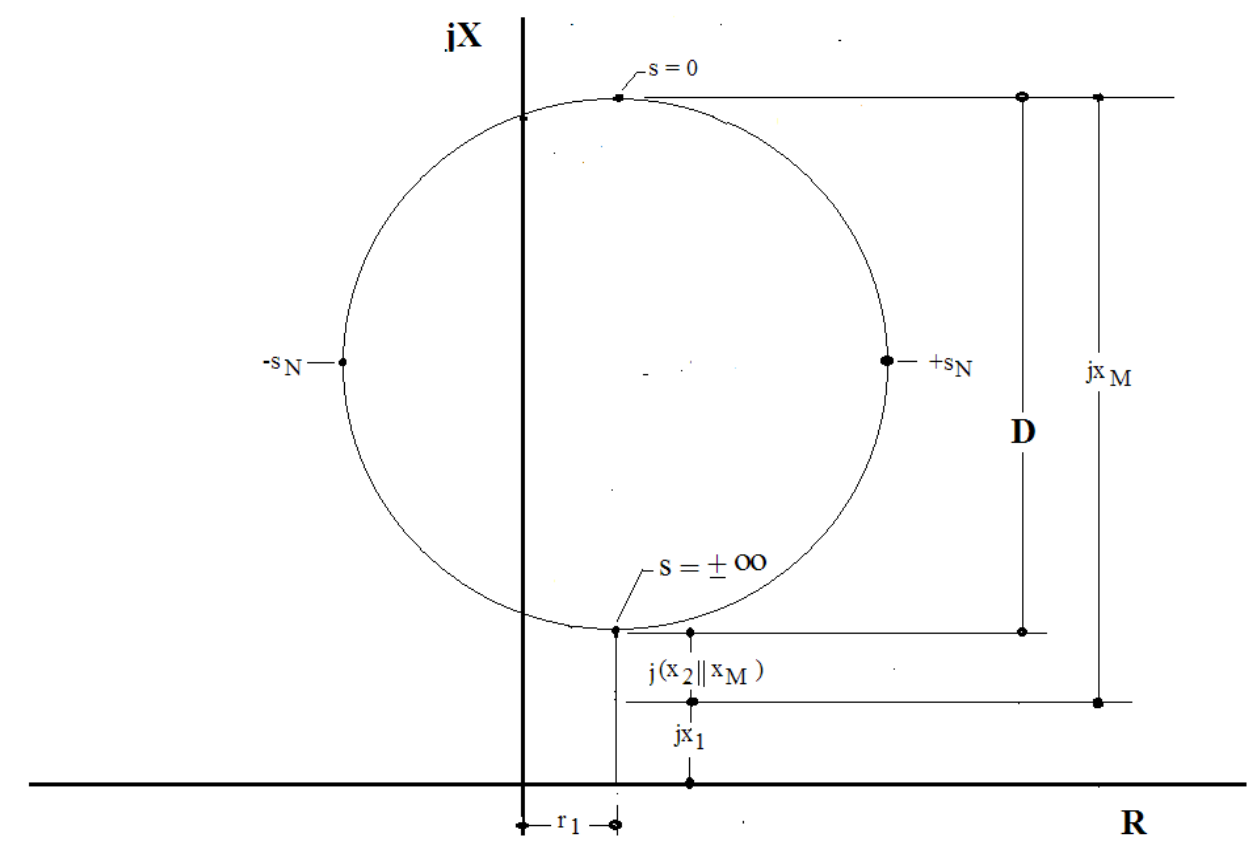

Figure 2. The Actual Impedance Locus of the Steinmetz Model

If all impedances in Figure 2 are divided by $\mathrm{D}$, and all peripheral slip values are divided by $\mathrm{s}_{\mathrm{N}}$, [the slip at the right-most extremity of the circle - see Equation (6)], the resultant plot is almost a Locus; it lacks only the locations of the normalized blocked rotor and no load and operating points, covered in 1.0 and 2.1 of the Appendix, respectively. The circular portion of Figure 2 becomes a Unit Circle, with a known position in the normalized complex impedance plane. As will be developed in the Appendix, the Locus for any given machine may also be obtained by starting with a generic Unit Circle, then locating the normalized resistance and reactance axes whose intersection yields the origin of that impedance plane, along with the no load and blocked rotor operating points noted above.

For any specific induction machine that is to be assessed, it is assumed that the following information is provided: the Locus for the machine, the machine constant D, and nameplate data (rated voltage, operating frequency, and the number of poles). The analyst is then required to determine the operating characteristics at a specific value of per phase current. The steps taken using the proposed graphical method are as follows:

1) Determine the magnitude of the actual impedance [Z] and normalized impedance [z]:

$$
\mathrm{Z}=\mathrm{Vp} / \mathrm{Ip} \text { and } \mathrm{z}=\mathrm{Z} / \mathrm{D}
$$

2) Using the calibrated scale of the vertical diameter of the Unit Circle, locate the operating point on the periphery of the Unit Circle at a distance [z] from the origin; then draw the Impedance Line on the Locus from the origin 0' to that operating point.

3) a) Three phase motor/single phase motor: draw the Resistance Line from the operating point $\mathrm{C}$ on the right hand periphery to the reactance axis at point $\mathrm{A}$; label the Loss Line intersection point B. 
b) Three phase generator: draw the Resistance Line from operating point $\mathrm{A}^{\prime}$ on the left hand periphery to the Loss Line point B; label the reactance axis intersection A.

4) Using the line segments from the resulting plot, along with phase current and the 'power equals $\mathrm{I}^{2} \mathrm{R}$ formula', determine values requested for the solution.

3.0 Numerical examples - a three-phase machine

Figure 3 contains the Locus, along with graphical steps 2) and 3) for motor operation; that same Locus will be used in section 3.2 for generator operation. For convenience, the operating currents have been particularly-selected so that the motor and generator Resistance Lines will be co-linear in Figure 3. More-obvious equations in the material that follows are not numbered.

\subsection{Motor operation.}

Given: The Locus shown in Figure 3 is provided for a certain three phase, four pole induction motor with a machine constant $\mathrm{D}$ equal to 20.0; the motor operates from an ideal source with a rated per phase voltage of 200 volts rms and a frequency of 60 Hertz.

Find: the following operating characteristics when the phase current is 19.4 amperes rms.

a) the efficiency, $\eta \quad$ (normally $\mathrm{P}_{\mathrm{O}} / \mathrm{P}_{\mathrm{IN}}$; $\mathrm{BC} / \mathrm{AC}$ for motor or $\mathrm{A}^{\prime} \mathrm{A} / \mathrm{A}^{\prime} \mathrm{B}$ for generator on Locus).

b) the power factor, pf (normally $\mathrm{P} / \mathrm{S}$ or $\mathrm{R} / \mathrm{Z}$; $\mathrm{AC} / 0^{\prime} \mathrm{C}$ or $\mathrm{AA}^{\prime} / \mathrm{O}^{\prime} \mathrm{A}^{\prime}$ on Locus).

c) the input power, $\mathrm{P}_{\mathrm{IN}}$ (proportional to line $\mathrm{AC}$ for motor; line $\mathrm{A}^{\prime} \mathrm{B}$ for generator).

d) the power losses, $\mathrm{P}_{\mathrm{L}}$ (proportional to line $\mathrm{AB}$ for motors and generators).

e) the delivered power, $\mathrm{P}_{\mathrm{O}}$ (proportional to line $\mathrm{BC}$ for motors and $\mathrm{A}^{\prime} \mathrm{A}$ for generators).

Solution:

1) Find the magnitude of the actual impedance and normalized impedance:

$$
\mathrm{Z}=\mathrm{V}_{\mathrm{p}} / \mathrm{I}_{\mathrm{p}}=200 / 19.4=10.3 \text { ohms } ; \quad \mathrm{z}=\mathrm{Z} / \mathrm{D}=10.3 / 20.0=0.515
$$

2) Using the calibrated scale of the Unit Circle vertical diameter, preferably with a draftsman's divider, locate operating point $\mathrm{C}$ on the right half of the Unit Circle periphery 0.515 divisions from 0 '; draw the Impedance Line from 0 ' to point $\mathrm{C}$.

3) Draw the Resistance Line from point $\mathrm{C}$ to the reactance axis point $\mathrm{A}$; also label the intersection with the Loss Line point B.

4) Calculate a) through e) in terms of the line segments on the Locus and the current.

Note that the efficiency and power factor values may be determined without evaluating the input or output power. 


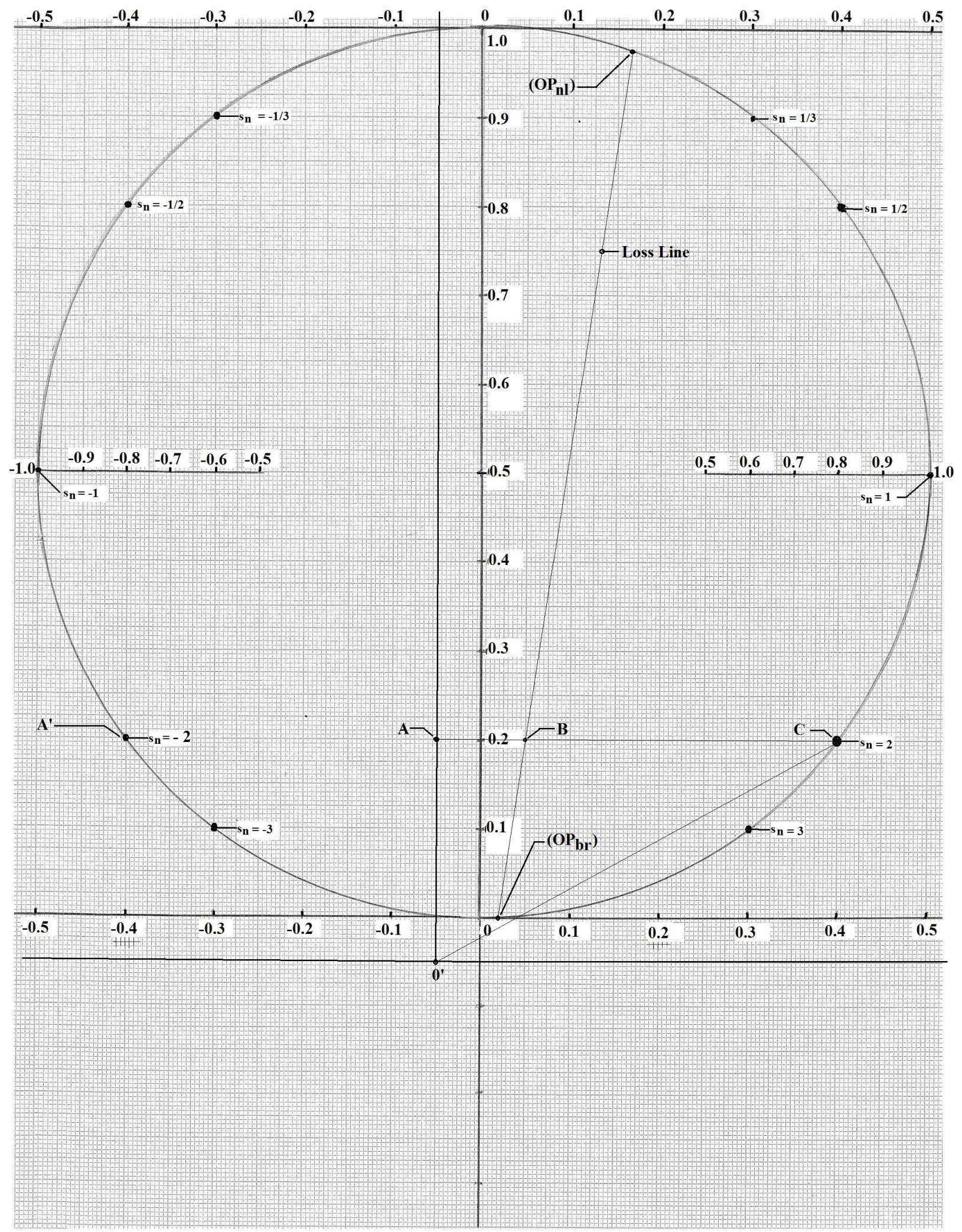

Figure 3. A plot that contains the reduced-size Locus for the three phase numerical examples along with steps 2) and 3) for motor operation. 
a) Efficiency: $\quad \eta=\mathrm{BC} / \mathrm{AC}=(0.35 / 0.45) \approx 0.78$ or $78 \%$

b) Power factor: $\quad \mathrm{pf}=(\mathrm{AC}) /\left(0^{\prime} \mathrm{C}\right)=(0.45 / 0.515) \approx 0.87$

c) Power in: $\quad \mathrm{P}_{\mathrm{IN}}=3\left(\mathrm{~V}_{\mathrm{p}}\right)\left(\mathrm{I}_{\mathrm{p}}\right)(\mathrm{pf})=3\left(\mathrm{I}_{\mathrm{p}}\right)^{2}(\mathrm{D})(\mathrm{AC})=3(19.4)^{2}(20.0)(0.45) \approx 10.2$ kilowatts

d) Power losses: $\quad \mathrm{P}_{\mathrm{L}}=3\left(\mathrm{I}_{\mathrm{p}}\right)^{2}(\mathrm{D})(\mathrm{AB})=3(19.4)^{2}(20.0)(0.1) \approx 2.3$ kilowatts

e) Power Out: $\quad \mathrm{P}_{\mathrm{O}}=\left(\mathrm{P}_{\mathrm{IN}}-\mathrm{P}_{\mathrm{L}}\right)=3\left(\mathrm{I}_{\mathrm{p}}\right)^{2}(\mathrm{D})(\mathrm{BC})=3(19.4)^{2}(20.0)(0.35) \approx 7.9$ kilowatts

This concludes the graphical analysis of the three-phase induction motor.

\subsection{Asynchronous generator operation}

The same machine is driven as a generator connected to the same ideal source: 200 volts rms per phase at 60 Hertz. Determine the following when the per phase current is 23.3 amperes rms:

a) The magnitude of complex, reactive and real power delivered. b) Power factor, pf.

$\begin{array}{lll}\text { c) Efficiency, } \eta & \text { d) Power into generator, } P_{G} & \text { e) Power Losses, } P_{L}\end{array}$

Solution:

1) Find the magnitude of the actual impedance and normalized impedance:

$$
\mathrm{Z}=\mathrm{V}_{\mathrm{p}} / \mathrm{I}_{\mathrm{p}}=200 / 23.3 \approx 8.6 \mathrm{ohms} ; \quad \mathrm{Z}=\mathrm{Z} / \mathrm{D}=8.6 / 20.0=0.43
$$

Steps 2) and 3): Locate point $\mathrm{A}^{\prime}$ on the left hand periphery at a distance of 0.43 from the origin 0'; draw Impedance Line 0'A' and Resistance Line segment A'B (neither is shown in Figure 3). Line $\mathrm{AB}=0.1$, still represents the machine losses, now provided by the prime mover.

4) Therefore the requested values are as follows:

a) Complex Power: $\mathrm{S}_{\mathrm{D}}=\mid 3\left(\mathrm{Vp}\left(\mathrm{I}_{\mathrm{p}}^{*}\right) \mid=3(200)(23.3) \approx 14.0 \mathrm{kVA}\right.$

Reactive Power: $\mathrm{Q}_{\mathrm{D}}=3\left(\mathrm{I}_{\mathrm{p}}\right)^{2}(\mathrm{D})\left(0^{\prime} \mathrm{A}\right)=3(543)(20)(0.25) \approx 8.1 \mathrm{kVAR}$

Real Power: $\quad \mathrm{P}_{\mathrm{D}}=3\left(\mathrm{I}_{\mathrm{p}}\right)^{2}(\mathrm{D})\left(\mathrm{AA}^{\prime}\right)=3(543)(20)(0.35) \approx 11.4 \mathrm{~kW}$

b) Power factor: $\mathrm{pf}=\left(\mathrm{AA}^{\prime}\right) /\left(0^{\prime} \mathrm{A}^{\prime}\right)=(-0.35 / 0.43) \approx-0.81$

c) Efficiency: $\eta=\mathrm{A}^{\prime} \mathrm{A} / \mathrm{A}^{\prime} \mathrm{B}=0.35 / 0.45 \approx 0.78$ or $78 \%$

d) Power into generator: $\mathrm{P}_{\mathrm{G}}=3\left(\mathrm{I}_{\mathrm{p}}\right)^{2}(\mathrm{D})\left(\mathrm{A}^{\prime} \mathrm{B}\right)=3(23.3)^{2}(20.0)(0.45) \approx 14.7 \mathrm{~kW}$

e) Power Losses, $\mathrm{P}_{\mathrm{L}}=3\left(\mathrm{I}_{\mathrm{p}}\right)^{2}(\mathrm{D})(\mathrm{AB})=3(23.3)^{2}(20.0)(0.1) \approx 3.3$ kilowatts

This completes the analysis of the three-phase asynchronous generator. 


\subsection{The Single Phase Induction Motor}

A traditional textbook 'double-revolving field model' for the running winding of a single phase machine consists of a series connection of $\mathrm{r}_{1}+\mathrm{jx}$, plus a Forward and Backward Impedance each of which is identical in form to $Z_{\mathrm{f}}$ of Figure 1. All elements in the model, except $\mathrm{r}_{1}$ and $\mathrm{jx}_{1}$ are halved. Valid assumptions simplify to a model similar to that of Figure 1 - with a backward resistance equal to $\mathrm{r}_{2} / 4$ added to the stator elements. The loss in that resistance is termed the Backward Power and accounts for the Adjusted Loss Line in Figure 4 (see Appendix 2.2).

A certain single-phase motor with the Locus shown in Figure 4 operates from a 120 volt rms, 60 Hertz power source. It is known that the machine constant, $\mathrm{D}=20.0$; determine the following when the phase current is 12.0 amperes:

a) the efficiency, $\eta$

b) power factor, pf

c) the power input, $P_{\mathbb{I N}}$

d) the power output, $P_{O}$

e) the total losses, $P_{L}$

1) As always, first determine the actual and normalized impedances

$$
\mathrm{Z}=\mathrm{Vp} / \mathrm{Ip}=120.0 / 12.0=10.0 \mathrm{ohms} \text { and } \mathrm{z}=\mathrm{Z} / \mathrm{D}=10.0 / 20.0=0.50 \mathrm{ohms}
$$

2) Using the scale of the vertical Unit Circle diameter, locate the operating point $C$ on the right hand periphery at a distance 0.50 from the origin; draw the Impedance Line $0^{\prime} \mathrm{C}$.

3) Draw the Resistance Line from operating point $\mathrm{C}$ to the reactance axis at point $\mathrm{A}$; label the intersection with the Adjusted Loss Line point B.

4) Determine the items requested in terms of the above line segments and the current.

a) $\quad \eta=(\mathrm{BC}) /(\mathrm{AC}) \approx(0.26) /(0.4) \approx 0.65$ or $65 \%$

b) $\left.\quad \mathrm{pf}=(\mathrm{AC}) /\left(0^{\prime} \mathrm{C}\right)=(0.4) / 0.5\right)=0.80$

c) $\quad \mathrm{P}_{\mathrm{IN}}=\left(\mathrm{V}_{\mathrm{p}}\right)\left(\mathrm{I}_{\mathrm{p}}\right)(\mathrm{pf})=\left(\mathrm{I}^{2}\right) \mathrm{D}(\mathrm{AC})=(144)(20)(0.4)=1152$ watts

d) $\quad \mathrm{P}_{\mathrm{O}}=\mathrm{P}_{\mathrm{IN}}(\mathrm{BC}) /(\mathrm{AC}) \approx(1152)(0.26) /(0.4) \approx 749$ watts

e) $\quad \mathrm{P}_{\mathrm{L}}=\mathrm{P}_{\mathrm{IN}}(\mathrm{AB}) /(\mathrm{AC})=\mathrm{P}_{\mathrm{IN}}-\mathrm{P}_{\mathrm{O}} \approx(1152)(0.14) /(0.4) \approx 403$ watts.

This concludes the analysis of a single phase induction motor. 


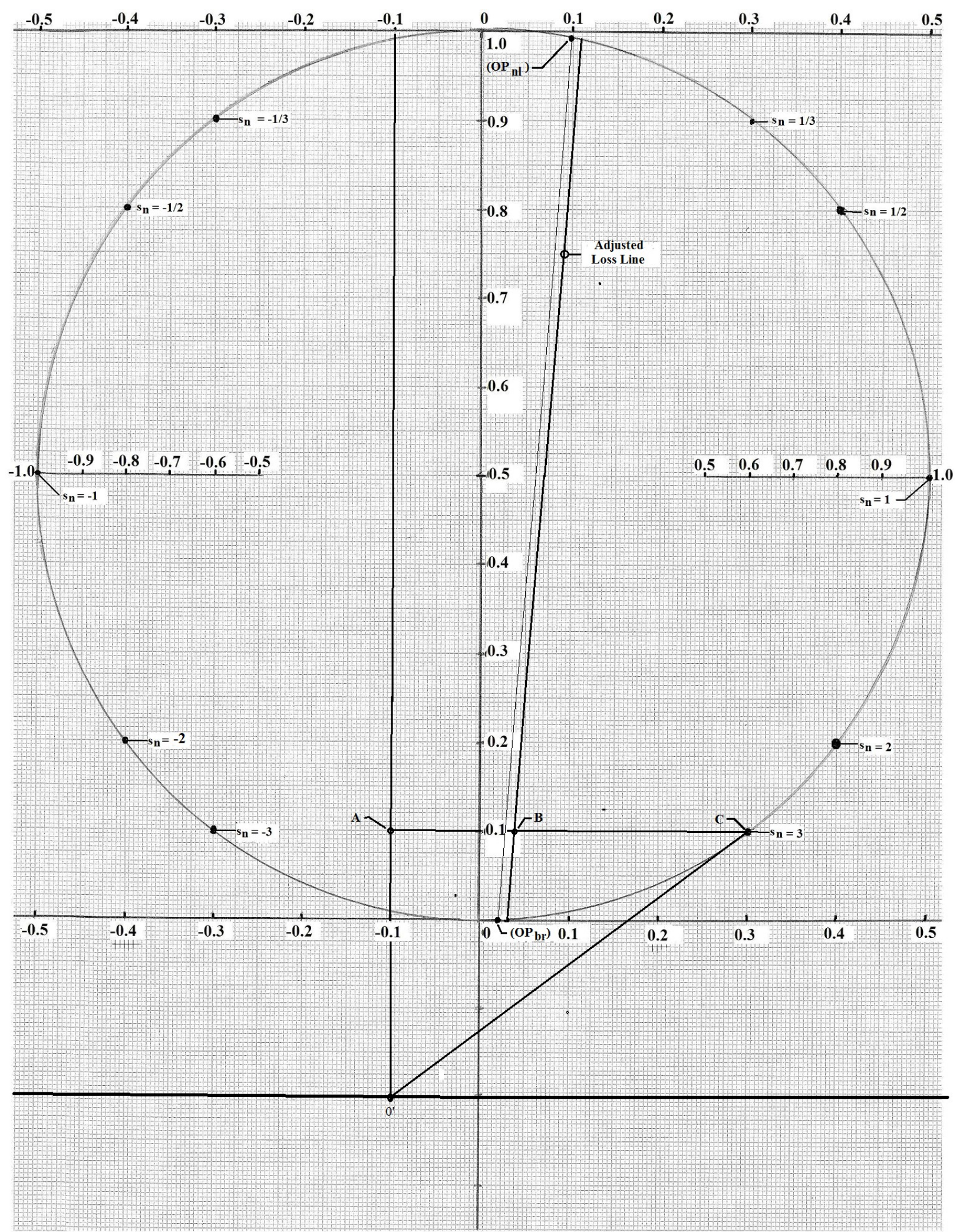

Figure 4. The Locus for the single phase machine along with graphical steps 2) and 3). 
4.0 Further advantages of using the graphical approach.

The starting current for a balanced multiphase machine, $I_{\text {st }}$, can be found as follows:

Measure the normalized blocked rotor Impedance Line $\mathrm{z}_{\mathrm{b}}$, the distance from the origin $0^{\prime}$ to $\left(\mathrm{OP}_{\mathrm{br}}\right)$; then $\mathrm{I}_{\mathrm{st}}$ is equal to the phase voltage divided by $\left[(\mathrm{D})\left(\mathrm{z}_{\mathrm{br}}\right)\right]$.

Having found the starting current, the starting torque is readily determined using the traditional textbook formula that states that the starting torque is equal to 'the power-to-the-rotor' divided by the angular velocity of the motor shaft at synchronous speed. The result is:

$$
\tau_{\mathrm{st}}=\left[3\left(\mathrm{I}_{\mathrm{st}}\right)^{2}(\mathrm{D})\left(\mathrm{S}_{\mathrm{N}}\right)\right] / \omega_{\mathrm{s}}
$$

The maximum and minimum theoretically-possible values of phase current can be found by drawing a line from the origin $0^{\prime}$ through the center of the Unit Circle to the far periphery. The distance from the origin to the far side of the Circle is $z_{\max }$ and the distance to the near side of the Circle is $Z_{\min }$. Given the per phase voltage and $\mathrm{D}$, the two current values are obtained apace. The minimum current value obtained is usually a good approximation to the no load current.

One can determine the current to be selected for machine operation at the center of the region of almost constant and maximum power factor [either as a motor or generator]. One locates the operating point at the intersection of two lines: the line from the origin that is tangent to the Unit Circle, and the radial line from the center of the Circle that is perpendicular to that tangent line. The normalized impedance at the maximum torque operating point is the distance from $0^{\prime}$ to their intersection; given the rated voltage and $\mathrm{D}$, the current magnitude is found using Ohm's law.

The operating point at breakdown torque can be approximated by drawing a circle with its center at the bottom of Unit Circle - and with a radius equal to the distance from that center to the impedance origin 0 '. The point where that circle intersects the periphery of the Unit Circle yields the breakdown torque point - and the corresponding Impedance Line and current. This procedure is essentially the graphical use of the maximum power theorem: equating the source impedance to the load impedance.

Rather than lumping the losses as in the numerical examples $3.1-3.3$ above, the analyst may determine individual machine losses illustrated in the semicircular Locus shown in a reference ${ }^{3}$; after finding the operating point shown as $s_{n}=0$ in that reference, two lines are drawn from that point: one to the bottom of the Circle (an approximation) and one to the normalized blocked rotor point. One can then selectively find the stator and rotor copper losses, the stator core loss and the rotational losses in terms of the machine constant [D], the horizontal line segments and the phase current. 


\subsection{Conclusions}

A graphical method has been described that uses the magnitude of the phase current, in lieu of per unit slip, to assess the performance of fixed-frequency single phase and/or balanced multiphase induction machines. The method eliminates the need for the computer/scientific calculator normally required to complete the traditional mathematical analysis of the IEEE Standard 112 model - or of the more simplified models routinely used in the numerical examples of traditional texts. In contrast, analysts need but draw two straight lines - and Impedance Line and a Resistance Line - on the Normalized Impedance Locus for a given machine in order to initiate a reasonably-accurate machine analysis; they may easily visualize how the operating point moves around the Unit Circle of the Locus as the machine phase current varies with load. Also in contrast to most texts, asynchronous generators and single phase induction motors are covered - and by the same general approach. Numerical examples are provided for a singlephase motor under running conditions and for a balanced three-phase machine - operating as a motor and as an asynchronous generator. An assessment may be made with reasonable accuracy so long as the generic Unit Circle contained within the Locus has a diameter of at least 20 centimeters. Care must be taken when using reproduced copies of the Locus since any distortion will cause inaccurate graphical results.

Resistive elements representing the rotor core loss and stray loss do not appear in the IEEE 112 model and are not accounted for in the Locus; as a consequence, the calculated values of the efficiency are high and those of the total losses are low in the numerical examples. To compensate partially for neglecting these two losses, the slightly larger value of the machine constant $\mathrm{s}_{\mathrm{N}}$ derived from the Two Element Model is used rather than the true value that may be obtained from the Forward Impedance of the model utilized.

The means for determining the values of per unit slip and shaft speed at a given operating point are not addressed in detail here but can be obtained from the Locus with little additional effort. Interested readers may contact the writer at the email address provided below for the details.

\section{References}

[1] H. H. Skilling, Electrical Engineering Circuits. John Wiley \& Sons, Inc. NYC, NY, 1957, pp $224-241$.

[2] IEEE Standard 112-96, IEEE Standard Test Procedure for Polyphase Induction Motors and Generators, IEEE NYC, NY, 1996

[3] D.L Skaar, "A Simplified Analysis of the Six-Element Model of a Three-Phase Induction Motor", IEEE Transactions on Education, Vol. 44, Number 3, August 1998. 


\section{Appendix}

Whereas the proposed method of analysis of induction machines - given the Locus plus minimal additional information - is simple, the justification for the method requires some detail. Manufacturers could surely provide the Locus for each induction machine model that they produce should they elect to do so. Until they do, instructors may choose to convert the generic Unit Circle into the Locus for any given machine for student use. Depending on the academic level and the major of their students, instructors may hold students responsible for as much of the following material as they deem appropriate.

\subsection{The Two Element Model and the Unit Circle}

The heart of the proposed graphical method is the Two Element Model of a machine; it is of such importance to induction machine analysis that it fully deserves upper case emphasis. The Model consists of the reflected rotor resistance $r_{2} / s$ (which includes the mechanical load on the motor shaft) connected in parallel with $\mathrm{jx}_{\mathrm{M}}$, the impedance that represents the mutual flux shared by the stator and rotor circuitry. Those two elements largely determine the running characteristics of an induction machine; the Model is shown in Figure 5 below. As an examination of the input impedance of that Model will verify, the resulting circular locus has a unique symmetry.

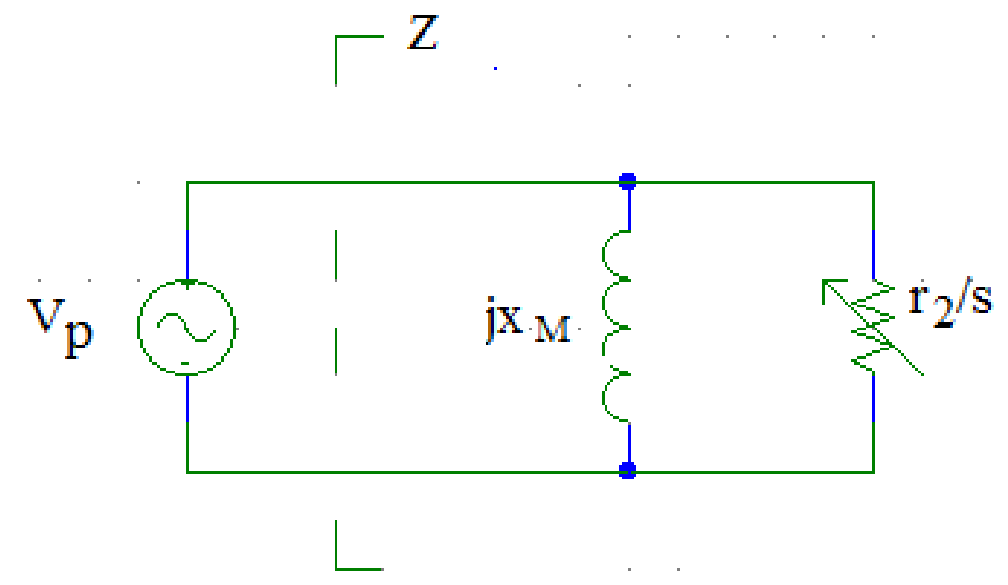

Figure 5. The Two-Element Model

Using the special two-branch 'product-over-sum impedance formula', the equation for the input impedance is:

$$
\mathrm{Z}=\left[\left(\mathrm{jx} \mathrm{x}_{\mathrm{M}}\right)\left(\mathrm{r}_{2} / \mathrm{s}\right)\right] /\left[\mathrm{r}_{2} / \mathrm{s}+\mathrm{jx_{ \textrm {M } }}\right]=\mathrm{jx} \mathrm{x}_{\mathrm{M}} /\left[1+\mathrm{j}\left(\mathrm{sx}_{\mathrm{M}} / \mathrm{r}_{2}\right)\right]
$$

Using the same approach with (5) as with the Forward Impedance in Equation (2) above

When $\mathrm{s}=0, \mathrm{r}_{2} / \mathrm{s}$ is an open circuit and so $\mathrm{Z}=\mathrm{j} \mathrm{x}_{\mathrm{M}}=\mathrm{Z}_{\mathrm{fmax}}$, its maximum value. When $\mathrm{s}$ is infinite, $\mathrm{r}_{2} / \mathrm{s}$ is a short circuit so $\mathrm{Z}=0=\mathrm{Z}_{\mathrm{fmin}}$, its minimum value. 
Again, the impedance locus of the Two Element Model is a circle with a diameter that is equal in magnitude to $\mathrm{x}_{\mathrm{M}}$, but of more importance from (5):

$$
\text { When } \left.s=r_{2} / x_{M}=s_{N}, Z=\left(j x_{M}\right) /(1+j 1)=\left[(0.707) x_{M}\right] \underline{45^{\circ}}\right]
$$

This point of operation is at the right hand extremity of the circular locus; $s_{N}$ is the second important machine constant used in the proposed analysis of induction machines. It calibrates the peripheral slip scale in terms of $\mathrm{s}_{\mathrm{n}}$; more importantly for the proposed analysis, it allows one to locate the normalized blocked rotor point as shown below. This approximate value of $\mathrm{s}_{\mathrm{N}}$ is used for both single and three phase machine analysis although a bit larger than the actual one.

Setting $\mathrm{r}_{2}$ and $\mathrm{x}_{\mathrm{M}}$ equal to 1.0 in (5) above (another normalization process), then rationalizing the resulting equation, one obtains [where $\mathrm{s}_{\mathrm{n}}$ is defined as $\left.\mathrm{s} / \mathrm{s}_{\mathrm{N}}\right]^{3}$ :

$$
\mathrm{z}=\mathrm{j} /\left(1+\mathrm{j} \mathrm{s}_{\mathrm{n}}\right)=\left[\mathrm{j}\left(1-\mathrm{j} \mathrm{s}_{\mathrm{n}}\right) /\left(1+\mathrm{s}_{\mathrm{n}}^{2}\right)=\left(\mathrm{s}_{\mathrm{n}}+\mathrm{j}\right) /\left(\mathrm{s}_{\mathrm{n}}^{2}+1\right)\right.
$$

If the term $s_{n}$ now takes on the values of zero, $( \pm 1 / 3),( \pm 1 / 2),( \pm 1),( \pm 2),( \pm 3)$ and infinity the corresponding values of the impedance are $(\mathrm{j} 1),( \pm 0.3+\mathrm{j} 0.9),( \pm 0.4+\mathrm{j} 0.8),( \pm 0.5+\mathrm{j} 0.5)$, $( \pm 0.4+\mathrm{j} 0.2),( \pm 0.3+\mathrm{j} 0.1)$ and zero, respectively. Those impedance values are plotted as a function of $s_{n}$ to obtain the reduced-size Unit Circle, or IODEKICE LOCUS, shown in Figure 6 below; again, the suggested diameter for the Unit Circle for graphical analysis is $20 \mathrm{~cm}$.

The symmetry of the resulting Unit Circle is quite remarkable with respect to both the horizontal diameter and the vertical diameter: a) reactances are equal for positive and negative values of $s_{n}$ of the same magnitude and $b$ ) resistances are equal for a given value of $s_{n}$ and its reciprocal.

Also, important information may be obtained by inscribing a right triangle in the right half plane of the Unit Circle with the $90^{\circ}$ angle at a given operating point - along with a perpendicular drawn to the reactance axis. A typical triangle and perpendicular are included on the Unit Circle of Figure 6 using very light lines, with the $90^{\circ}$ angle at $s_{n}=3.0$ as in the three phase examples. The value of the normalized slip, $\mathrm{s}_{\mathrm{n}}$, at that operating point may be found by either taking the tangent of the acute angle at the bottom of the Circle $(0.3 / 0.1=3.0)$, or taking the cotangent of the acute angle at the top of the Circle $(0.9 / 0.3=3.0)$. The apparent per unit slip, obtained by multiplying $s_{n}$ by the machine constant $s_{N}$, is not corrected for the effect of $r_{\text {fe }}$ previously noted ${ }^{3}$.

Again of more importance here, the normalized blocked rotor point $\left(\mathrm{OP}_{\mathrm{br}}\right)$ may be obtained using the cotangent relationship noted above. The normalized value of $s_{n}$ at that operating point is $1 / s_{N}$; using the above-noted cotangent, that point is obtained by going from the top of the Circle to the bottom (a value of 1.0) - and then to the right by the distance $\mathrm{s}_{\mathrm{N}}$.

2.0 Verifying the validity of the three phase and single phase Locus provided.

The first step in the verification process is to find the machine constants, D and $\mathrm{s}_{\mathrm{N}}$ for the particular machines addressed in the numerical examples. After those constants are evaluated, one may locate the resistance and reactance axes, and the normalized no load and blocked rotor operating points $\left(\mathrm{OP}_{\mathrm{nl}}\right)$ and $\left(\mathrm{OP}_{\mathrm{br}}\right)$ on the Circle periphery. 


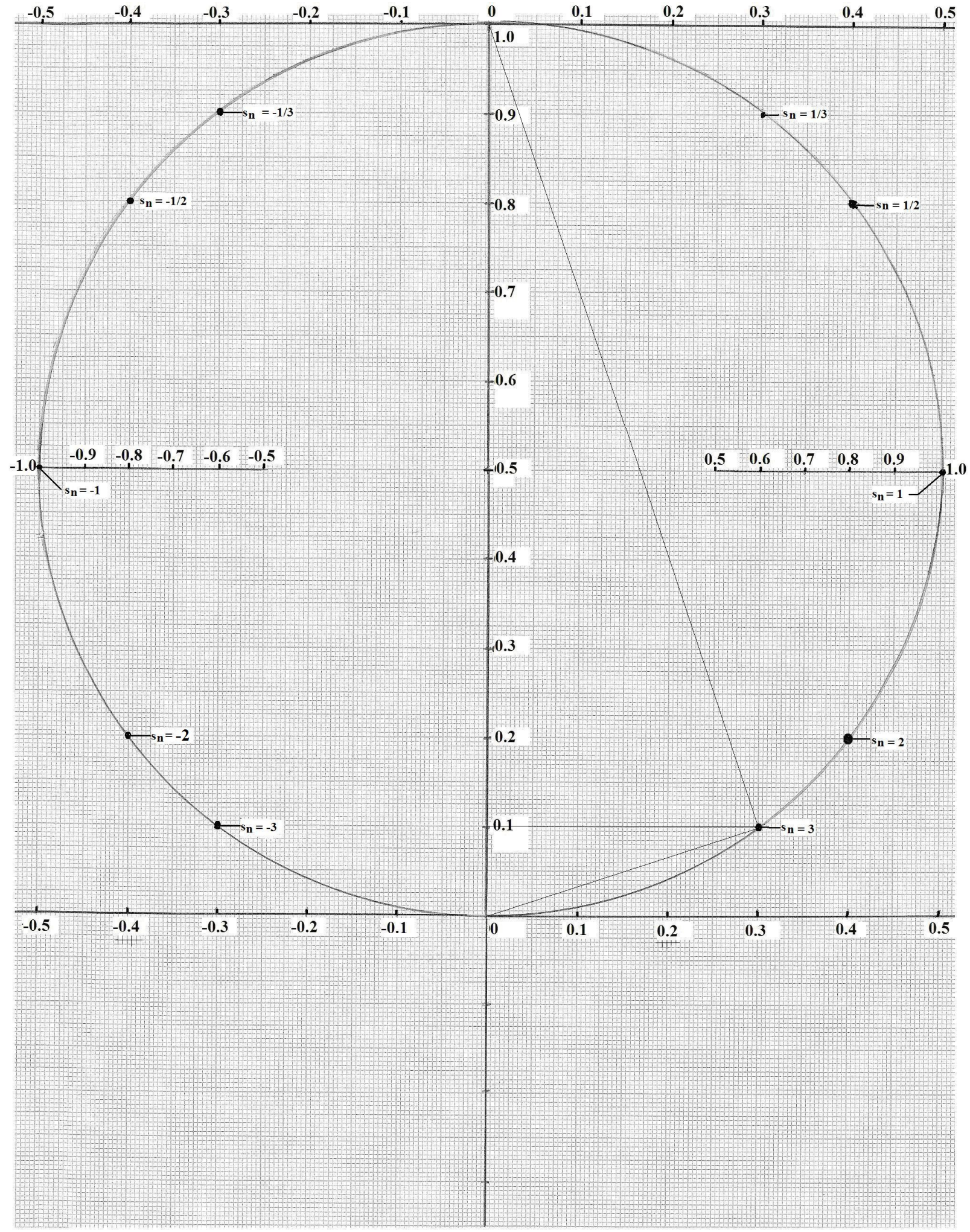

Figure 6. A miniaturized Unit Circle (IODEKICE LOCUS) with inscribed right triangle and perpendicular. 


\subsection{The three phase machine.}

The element values and no load data for the four pole, 200 volt per phase, 60 Hertz three phase machine used in the numerical examples are given as follows:

$$
\begin{array}{rlrl}
\mathrm{r}_{1} & =1.0 \mathrm{ohms} & \mathrm{r}_{2}=0.41 \mathrm{ohms} \\
\mathrm{X}_{1}=0.50 \mathrm{ohms} & \mathrm{X}_{2}=0.51 \\
\mathrm{X}_{\mathrm{M}}=20.5 \mathrm{ohms} & \mathrm{r}_{\mathrm{fe}}=205 \mathrm{ohms} \\
\mathrm{P}_{\mathrm{NL}}=1370 \text { watts } & \mathrm{I}_{\mathrm{nl}}=10.3 \mathrm{ampe}
\end{array}
$$

Using equation (3): $\quad \mathrm{D}=\left[\mathrm{x}_{\mathrm{M}}-1 /\left(1 / \mathrm{x}_{\mathrm{M}}+1 / \mathrm{x}_{2}\right)\right] \approx[20.5-0.5]=20.0$

Using the Two Element Model value, the machine constant $\mathrm{s}_{\mathrm{N}}$ is used to locate $\left(\mathrm{OP}_{\mathrm{br}}\right)$ :

$$
\mathrm{S}_{\mathrm{N}} \approx\left(\mathrm{r}_{2} / \mathrm{x}_{\mathrm{M}}\right)=(0.41 / 20.5)=0.02
$$

Observing Figure 2, with all impedances divided by D, the reactance axis is located to the left of the Unit Circle vertical diameter by the distance $r_{1} / D$; the resistance axis is located below the Circle by the distance $\left[\mathrm{x}_{1}+1 /\left(1 / \mathrm{x}_{\mathrm{M}}+1 / \mathrm{x}_{2}\right)\right] / \mathrm{D} \approx\left(\mathrm{x}_{1}+\mathrm{x}_{2}\right) / \mathrm{D}$ :

$$
\left.\mathrm{r}_{1} / \mathrm{D}=(1.0 / 20.0)=0.05 ; \quad\left(\mathrm{x}_{1}+\mathrm{x}_{2}\right) / \mathrm{D} \approx(1.0) / 20.0\right)=0.05
$$

The normalized no load operating point $\left(\mathrm{OP}_{\mathrm{nl}}\right)$ is located near the top of the Circle at a horizontal distance from the reactance axis equal to $\mathrm{r}_{\mathrm{n}}$; that value is obtained from the no load data:

$$
\mathrm{r}_{\mathrm{nl}}=\mathrm{P}_{\mathrm{NL}} / 3(\mathrm{D})\left(\mathrm{I}_{\mathrm{nl}}\right)^{2}=1370 / 3(20.0)(10.3)^{2} \approx 0.215
$$

The above values conform reasonably well with the Locus shown in Figure 3.

\subsection{The single phase machine.}

The element values of the running winding and no load data for the four pole, $60 \mathrm{Hertz}, 120$ volt single phase machine used in the numerical example are as follows:

$$
\begin{array}{lll}
\mathrm{r}_{1}=1.8 \text { ohms } & \mathrm{r}_{2}=0.84 \mathrm{ohms} & \mathrm{x}_{1}=2.0 \mathrm{ohms} \\
\mathrm{x}_{2}=2.1 \mathrm{ohms} & \mathrm{x}_{\mathrm{M}}=42.0 \mathrm{ohms} & \mathrm{r}_{\mathrm{fe}}=840 \mathrm{ohms} \\
\mathrm{I}_{\mathrm{nl}}=4.93 \text { amperes } & \mathrm{P}_{\mathrm{NL}}=97.3 \text { watts } &
\end{array}
$$

The constant $D$ is again equal to $Z_{\max }$ minus $Z_{\min }$ as in (3), but recalling that the elements of the Forward Impedance for a single phase machine are halved, the machine constant $\mathrm{D}$ is:

$$
\mathrm{D}=\left[\mathrm{x}_{\mathrm{M}}-1 /\left(1 / \mathrm{x}_{\mathrm{M}}+1 / \mathrm{x}_{2}\right)\right] / 2=[42.0-2.0] / 2=20.0
$$


Since $\mathrm{s}_{\mathrm{N}}$ is the ratio of two halved numbers, it remains the same as for a three phase machine. Once again the Two Element Model value will be used even though it is slightly larger than that obtained from Forward Impedance of the single phase model - and again it partially compensates for the fact that the rotor core loss and stray losses are not considered.

$$
\mathrm{S}_{\mathrm{N}} \approx\left(\mathrm{r}_{2} / \mathrm{x}_{\mathrm{M}}\right)=0.84 / 42.0=0.02
$$

The resistance axis is drawn below the Unit Circle at a distance that may be usually approximated by $\left[\mathrm{x}_{1}+\mathrm{x}_{2}\right] / \mathrm{D}$, when $\left(\mathrm{x}_{\mathrm{M}}>>\mathrm{x}_{2}\right)$ - the usual case:

$$
\left[\mathrm{x}_{1}+\mathrm{x}_{2}\right] / \mathrm{D} \approx[2.0+2.1] / 20.0 \approx 0.20
$$

The reactance axis is located to the left of the Circle vertical diameter by the distance

$$
\left.\left[\mathrm{r}_{1}+\left(\mathrm{r}_{2} / 4\right)\right] / \mathrm{D}=[1.8+0.84 / 4)\right] / 20.0 \approx 2.0 / 20.0=0.10
$$

The normalized blocked rotor point is again at a distance of $\mathrm{s}_{\mathrm{N}}$ to the right of the bottom of the Unit Circle.

$$
\mathrm{s}_{\mathrm{N}} \approx\left(\mathrm{r}_{2} / \mathrm{x}_{\mathrm{M}}\right)=0.02
$$

The normalized no load point is at a horizontal distance of $r_{n l}$ to the right of the reactance axis near the top of the Unit Circle:

$$
\mathrm{r}_{\mathrm{nl}}=\mathrm{P}_{\mathrm{NL}} /(\mathrm{D})\left(\mathrm{I}_{\mathrm{nl}}\right)^{2}=97.3 /(20.0)(4.93)^{2} \approx 0.20
$$

The Adjusted Loss Line shown in Figure 4 - which is drawn to the right of, and parallel to, the usual Loss Line (not labeled) - accounts for the Backward Power that must be subtracted from the Forward Power to obtain the actual output power in a single phase machine. That line is drawn at a distance $\left(\mathrm{r}_{2} / 4\right) / \mathrm{D}$ equal to:

$$
\left(\mathrm{r}_{2} / 4\right) / \mathrm{D}=(0.84 / 4) / 20.0 \approx 0.01
$$

Observing Figure 4, it can be seen that the above calculations verify the dimensions and the points on the periphery of the Locus for the single phase machine.

The results of a) through e) in sections $3.1-3.3$ of the paper were compared with those of a Spice program using the data in Appendix 2.1 and 2.2 just above; in that program the values of $r_{2} / s$ and $r_{2} / 2 s$ were varied, respectively for the three phase and single phase machine, until the per phase current values postulated in the numerical values were obtained. The correlation between the results was most reasonable. The largest percentage differences were in the efficiency and power factor values for the three phase machine and were less than $2 \%$. The differences were attributed to the use of the approximate value of $\mathrm{s}_{\mathrm{N}}$ obtained from the Two Element Model, rather than the more-accurate equation for that machine constant shown in II(2) of the reference ${ }^{3}$.

This concludes the Appendix. 